\title{
A experiência da Ação Cultural Hip-Hop sob o Viaduto de Madureira no Rio de Janeiro'
}

\author{
Emika Takaki \\ Arquiteta e Urbanista, doutoranda em Urbanismo pelo Programa \\ de Pós-Graduação em Urbanismo da Universidade Federal do Rio \\ de Janeiro, Rua Marquês de Olinda, 10, Botafogo, Rio de Janeiro, \\ RJ, CEP 22210-040, (21) 3281-8684, e.takaki@gmail.com
}

\section{Glauci Coelho}

Arquiteta e Urbanista, doutoranda em Urbanismo pelo Programa de Pós-Graduação em Urbanismo da Universidade Federal do Rio de Janeiro, Rua Soldado Aldemar Ferrugem, 15, Campo Grande, Rio de Janeiro, RJ, CEP 23080-750, (21) 3394-3953, glaucicoelho@yahoo.com.br

\begin{abstract}
Resumo
Buscamos dar visibilidade ao Movimento Hip-Hop como ação cultural capaz de potencializar a revitalização de espaços públicos residuais nas cidades contemporâneas. Trazemos o exemplo do espaço sob o Viaduto de Madureira no Rio de Janeiro, que teve não somente a sua imagem de simples lugar de passagem transformada, como o seu significado, ao se converter em lugar de encontro através das atuações do "Espaço Cultural Rio Hip-Hop Charme" e da "CUFA Madureira". Nossa construção teórica foi baseada em pesquisa em campo e em sites oficiais da CUFA e do Movimento Hip-Hop, além de argumentações teóricas sobre culturas híbridas, ação cultural e espaço público trazidas por diversos autores.
\end{abstract}

Palavras-chave: espaço público, lugar, ação cultural.

${ }^{1}$ O presente artigo foi selecionado para ser apresentado na Sessão Temática 7 - Território, cultura e identidades, do XIII ENAnpur Encontro Nacional da Anpur 2009

2 Usamos o termo urbanidade como um conjunto de aspectos sociais, culturais e econômicos que podem induzir o processo de construção de pertencimento do indivíduo, grupo social ou mesmo uma comunidade com toda sua diversidade à vida pública urbana, por meio da ação participativa comunitário, ao considerarmos que este processo possa

\section{ontextualização}

Há muito se debate a "morte das cidades" relacionada à apropriação dos espaços públicos pelo automóvel. Jane Jacobs (2000) inicia este debate que traz à tona a perda do espaço público como lugar do encontro, dando lugar às grandes vias e viadutos que entrecruzam as cidades. No tocante, esta onda rodoviarista também se implantou na cidade do Rio de Janeiro representando, para alguns espaços centrais da cidade e principalmente para os suburbanos, a ruptura do tecido urbano e perda de vitalidade dos espaços livres públicos as margens de tais intervenções, que convencionamos aqui chamar de "espaços residuais",

[aquele que] sobra entre os espaços privados ocupados (...) um espaço forçosamente sem forma própria, sem sistema simbólico preciso e sem nome, insignificante e inominável no sentido etimológico da palavra (HUET, 2001, p.147).

Ao considerarmos tal problemática, lembramos que para Richard Sennett (1993), na cidade contemporânea, a rua assume a identidade de mero espaço de circulação e movimentação, e neste aspecto perde o sentido de estar, o de encontro da vida pública. Assim, ainda com base nas argumentações do autor (p.32) "o homem moderno perdeu a oportunidade da experimentação que as ruas Ihe ofereciam por trocar o simples caminhar pela correria dos automóveis". A rua, outrora lugar de encontro da vida pública carregada de urbanidade², converte-se então, em alguns locais da cidade, em um não-lugar como já enunciado por Augé (2001), ou seja, aquele que representa nada mais que o espaço de circulação também citado por Sennett. 
se estabelecer das relações de cordialidade ou não com o outro, mas sempre no sentido da constituição cidadã.

${ }^{3}$ http://www.cufa.org.br.

${ }^{4}$ http://www.pcg.com.br/ eblack/36.htm.
Com base nas argumentações colocadas, trazemos para o centro do debate, o quão a apropriação por ações culturais dos espaços residuais oriundos da construção de viadutos pode se colocar como uma possível forma de revitalizar estes espaços, que não só recuperam seu sentido de lugar de encontro da vida pública, mas principalmente, se converte em ambientes que passarão a refletir uma nova imagem identitária para a cidade e/ou bairro, ao se tornarem um lugar simbólico, culturalmente vivido.

Ressaltamos que, com base nos pensamentos de Faria (2003, p.42), a presença de grupos culturais na vida comunitária pode contribuir na junção de novos fios do tecido invisível da cultura, e lança novas luzes sobre um mundo que parece ter perdido a capacidade de encantar-se. Com efeito, é necessário compreender que o acesso à cultura universal deve ser combinado com a valorização dos processos criativos dos grupos e movimentos culturais da comunidade, para que a sua experiência, o seu saber e a sua visão de mundo interpenetrem o tecido social e gere uma nova qualidade de vida, diferente da aridez da "modernidade" impulsionada pela homogeneização cultural.

Dessa forma acreditamos que a presença das diversas "manifestações culturais urbanas" na cidade contemporânea não exclui culturas e não faz uma predominar sobre a outra, mas sim, as hibridizam, recriando, entre outras, uma nova "cultura de rua". Para Canclini (2000, p.19) a hibridação é o resultado de combinações interculturais, termo que se torna apropriado para se referir à "cultura de rua", uma vez que este processo,

(...) abrange diversas mesclas interculturais não apenas raciais, às quais costuma limitar-se o termo "mestiçagem" - e porque permite incluir as formas modernas de hibridação, melhor do que "sincretismo", fórmula que se refere quase sempre a fusões religiosas ou de movimentos simbólicos tradicionais (CANCLINI, 2000, p.19).

Analisamos então como exemplo em nosso ensaio, o Movimento Hip-Hop no Brasil, que entendermos ser uma cultura de rua híbrida, que possui a potencialidade de resgatar ou transformar os espaços residuais da cidade como lugar de vivência. Observamos que segundo Carmo "o termo Hip-Hop engloba todas as manifestações de rua: dos Rappers aos DJ's, dos dançarinos de break aos graffiteiros. Não é só música, é uma cultura de rua" (CARMO, 2003, p.176).

Assim, para caracterizarmos o Hip-Hop, como uma cultura de rua híbrida e ao mesmo tempo ação cultural, teceremos considerações sobre a cultura enquanto instrumento de inclusão social com base, principalmente, nas argumentações de Werthein e Faria e em seguida uma breve exposição de como o movimento Hip-Hop se estabelece no cenário mundial, bem como nacional, aproximando este processo do que Teixeira Coelho, Duhamel e Jeanson elaboram sobre "ação cultural", e Canclini sobre "cultura híbrida".

Em continuidade as nossas argumentações, exploramos as ações culturais do Hip-Hop que se materializam sob o Viaduto de Madureira no Rio de Janeiro, através do Espaço Cultural Rio Hip-Hop Charme e do Centro Cultural da CUFA Madureira. Lembramos que a pesquisa sobre as atuações destes movimentos foi construída a partir de pesquisa de campo entre outubro e novembro de 2008, através de entrevistas não estruturadas com integrantes da CUFA-Madureira, bem como de pesquisas nos sites oficiais da CUFA ${ }^{3}$ e do Movimento Black ${ }^{4}$, entre outros relacionados ao tema.

Toda a argumentação construída nos revelou que as ações culturais do Hip-Hop em Madureira na Cidade do Rio de Janeiro não só contribuem para a recuperação do sentido de lugar para o espaço residual conformado pelo viaduto, mas também se converteram numa nova identidade para o bairro de Madureira, que já tinha a sua imagem associada ao Jongo, existente na comunidade da Serrinha, e ao Samba, o que, em certa medida explica a forte vocação e ligação local com a construção cultural negra.

\section{Considerações sobre cultura}

A cultura é considerada um "catalisador" de urbanidades e um instrumento de inclusão social, pois pode potencializar e estimular o sentimento de pertencimento e identidade cultural de comunidades excluídas. Com efeito, torna-se válido delinear sobre os percursos e uso da cultura nos projetos e políticas urbanas contemporâneas. Werthein (2003) 
aponta que a cultura é "capital social" capaz de mobilizar,

"por estimular o sentimento de pertencimento a um projeto coletivo, a participação, a promoção de atitudes que favoreçam a paz e o desenvolvimento sustentado, o respeito a direitos, enfim, a capacidade da pessoa humana e das comunidades de regerem o seu destino" (WERTHEIN, 2003, p.16).

Nesse sentido, a cultura aparece como um espaço social privilegiado de práticas, representações, símbolos e rituais que os jovens buscam para demarcar suas identidades. Tal potencial da cultura se confirma na colocação feita por Gilberto Gil, quando ele aponta que esta se constitui no espaço social como um "eixo construtor das identidades, como espaço privilegiado de realização da cidadania e de inclusão social e, também, como fato econômico gerador de riquezas" (GIL, 2003, p.9).

O que se observa com isso é o deslocamento da cultura de uma posição subordinada para uma posição estratégica nas políticas urbanas contemporâneas. Os projetos de cunho social as ações culturais buscam evidenciar a cultura local, a partir do resgate da identidade, do envolvimento da população e da inclusão social. Assim, passam a ser o principal objeto em projetos e políticas voltadas para Cultura.

Neste âmbito, observa-se um crescente número de ações culturais que visam à promoção da identidade local e inclusão social. Na maioria dos casos, o espaço público rua passa a ser o "palco" de muitas destas manifestações culturais. Neste aspecto, lembramos que para Faria (2003),

(...) a rua é o reino da comunidade. Podemos dizer que ela é o lugar por excelência das manifestações

5 [Nota dos Autores]

${ }^{6}$ Ibidem.

7 [Tradução dos Autores] do original citado por Caune (1996, p.171). «(...) I'action culturelle a donc désormais un rôle fondamental à jouer pour contrebalancer les effets néfastes de la croissance. Elle doit permettre aux hommes non seulement d'avoir plus, mais d'être plus» (DUHAMEL, J. L'Ère de la culture. Revue des deux mondes, septembre, 1972). culturais da comunidade. [Assim, como local mais próximo à comunidade.] $]^{5}$ A experiência demonstrou que os lugares culturalmente apropriados pela população têm sido valorizados. (...) Há hoje uma ida às ruas pró-movimentos culturais. (FARIA, 2003, p.40)

Dentro da construção exposta acima, a rua é o local perfeito para a materialização das ações culturais, e o movimento Hip-Hop converteu-se numa das formas de comunicação mais eficazes das periferias com as outras partes da cidade. Em outras palavras, é a atuação das periferias sociais, onde o Hip-Hop é aquele que convida à manifestação da vida pública, convertendo-se ele mesmo no próprio espaço (lugar), e que é propício à construção e afirmação de identidades ao mesmo tempo em que cria o espaço físico para sua manifestação. Como citado por Martins (2005, p.41), neste [espaço público Hip-Hop] ${ }^{6}$, os jovens criam espaços próprios de urbanidade que se transformam em territórios culturalmente expressivos nos quais diferentes identidades são elaboradas.

Ao se valorizar esses movimentos culturais como territórios culturalmente expressivos criam-se possibilidades de trocas entre um número mais expressivo de atores sociais. Neste processo leva-se em consideração as diferenças e as experiências. Cria-se ainda condições para que a sociedade cresça e melhore ao valorizar a diversidade que se manifesta através dos movimentos culturais das periferias sociais.

\section{A cultura híbrida do Hip-Hop no Brasil potencializada como ação cultural}

O lugar a partir do qual vários artistas latinoamericanos escrevem, pintam ou compõem músicas, já não é a cidade na qual passaram sua infância, nem tampouco é essa na qual vivem há alguns anos, mas um lugar híbrido, no qual se cruzam os lugares realmente vividos (CANCLINI, 2006, p.327).

Tratamos aqui da ação cultural como ação integradora de culturas no sentido que a democratização cultural nada mais é, também, do que promover e celebrar a cultura do outro. Neste aspecto nos apoiamos de início no estudo que Teixeira Coelho (1997) desenvolve sobre políticas culturais, para trazermos à tona a noção de ação cultural como a procura do "pleno desfrute de uma obra, o que envolve o entendimento dos seus aspectos formais, de conteúdo, sociais e outros" (p.32). Dentro desta contextualização, partimos também, do pressuposto que esta idéia traz em si o sentido de identificação do indivíduo ou grupo, bem como o de identificação do próprio lugar aonde todos os atores envolvidos se socializam como uma possível resposta ao crescimento das cidades, não somente no sentido de ter, mas também no de ser, já como enunciado por Duhamel ${ }^{7}$ (DUHAMEL apud CAUNE, 
8 Segundo DJ Groovy (EBLACK, 2008), "Kool Herc é por toda parte conhecido e respeitado como o "pai" da cultura Hip-Hop, ele contribuiu e muito para seu nascimento, crescimento e desenvolvimento. Nascido na Jamaica, ele imigrou em 1967 (aos 12 anos de idade) de Kingston para Nova lorque, trazendo seu conhecimento sobre a cena de Sound system (sistema de som, muito tradicional na Jamaica, seria um equipamento de som muito potente ligado na rua para atrair as pessoas)"

${ }^{9}$ Milton Salles foi produtor dos Racionais Mc's até 1995 hoje em dia é responsável pela Companhia Paulista de Hip-Hop, que continua tendo o mesmo intuito divulgar a cultura do Hip-Hop (E-BLACK, 2008).

${ }^{10}$ Segundo Safire, o RAP é "um neologismo popular do acrônimo para rhythm and poetry (ritmo e poesia); porém, apesar da associação com poesia e ritmo, o significado da palavra rap não é um acrônimo em si, mas descreve uma fala rápida que precede a forma musical (de ritmo e poesia), e significa "bater" A palavra (rap) é usada no Inglês britânico desde o século XVI, e especificamente significando "say" ("dizer", ou "falar", "contar o conto") desde o século XVIII. Fazia parte do Inglês vernáculo afro-americano nos anos de 1960, significando "conversar", e logo depois disto, no seu uso atual, denota o estilo musical". SAFIRE, William. On Language: The rap on Hip-Hop-hop. The New York Times Magazine. In: http:// pt.wikipedia.org/wiki/Rap.

11 JEANSON, Francis. L'Action culturelle dans la cite. Paris: Le Seuil, 1973.

12 [Nota dos autores]
1996, p.171), e que se converge aqui no sentido de permanência - de estar e pertencer.

Acreditamos que são os laços culturais e identitários que unem indivíduos e enraízam comunidades. $\mathrm{Na}$ atualidade, culturas e identidades coletivas e distintas são postas lado a lado, propiciando muitas vezes novas culturas frutos de mesclas sócio-culturais. $\mathrm{Na}$ maioria das vezes culturas são desterritorializadas e encontram novas materialidades em diferentes culturas, assumem novos aspectos, são nas palavras de Teixeira Coelho culturas híbridas (1997, p.125), que para Canclini (2000, p.19) resultam das diversas mesclas interculturais.

Assim sendo, damos destaque à cultura de rua do movimento Hip-Hop ${ }^{8}$ no Brasil como exemplo do processo de hibridização cultural, uma vez que esta tem sua origem, segundo DJ Groovy (E-BLACK, 2008), nas ruas do subúrbio de Nova lorque nos Estados Unidos, e chega ao Brasil na década de 1980, e ao longo da construção da sua presença aqui recebe influencias de culturas locais.

Contudo, àquela época, ainda não existiam movimentos que retratavam exatamente seu fundamento, o significado na íntegra desta cultura, que tem como idéia inicial a disputa com criatividade, sem armas, "uma batalha de diferentes (e melhores) estilos, para transformar a violência insensata em energia positiva" (DJ GROOVY, E-BLACK, 2008). Tal ideologia foi difundida no Brasil inicialmente com o Break Dance, que tem como ano oficial a chegada da Dança de Rua no Brasil 1984. Entretanto, foi em São Paulo que se concentrou primeiro o movimento Hip-Hop, mais precisamente na Rua 24 de Maio, se deslocando posteriormente para a Estação São Bento do metrô. Neste período ocorre uma divisão, e outro grupo se estabelece na Praça Roosevelt que dá origem ao "Sindicato Negro". Em agosto de 1989, Milton Salles ${ }^{9}$ criou a $\mathrm{MH}^{2} \mathrm{O}$ "Movimento Hip-Hop Organizado".

A presença de Salles no movimento foi muito importante, pois ele cria várias oficinas nas periferias, shows gratuitos nos guetos e divulgou muito o RAP ${ }^{10}$ para o grande público (DJ GROOVY, E-BLACK, 2008). Percebemos com isto que desde o seu início, o Movimento deixa transparecer o seu potencial transformador de realidades, ou seja, a capacidade que ele tem para transformar em ação social sua cultura, que encontra no Brasil grande acolhida, e que é em parte devido ao fato da cultura Hip-Hop representar um lugar de construção identitária, o espaço propício à construção e reafirmação de identidade como citado anteriormente por Martins (2005, p.41), em que a periferia se coloca não mais como ator social coadjuvante, mas sim como uns dos centros de criação cultural

Importante observa que o Hip-Hop se desenrola e se enraíza como cultura de rua apoiada em quatro pilares que se converteram nas suas formas de comunicação: o músico denominado "DJing" que é o criador de sons para o Rap, e que descobre e cria os "Break-beats"; o "B.BOYing" que representa a dança, e que nasce dos "Breaks" das canções; o "MCing", Mestre de Cerimônia que representa o canto; e, o "WRITing", que são os escritores e/ ou graffiteiros representantes da arte plástica, expressa basicamente em paredes utilizando o spray. E é através desta forma de se comunicar que o Hip-Hop se estabelece como um estilo de vida, com forte cunho ideológico (DJ GROOVY, E-BLACK, Op. Cit.).

O cunho ideológico desse movimento traz a marca forte da presença dos negros nos guetos norte americanos, e no Brasil não é diferente. O HipHop tem por natureza o protesto que reinvidica a presença da periferia urbana como ator social ativo não sujeito a cultura da outro, mas atuante no processo de formação da sociedade, e é neste sentido que consideramos tal cultura como "ação cultural", a própria cultura como "ação", uma vez que se estabelece no cenário urbano como um "processo de criação e organização das condições necessárias para que as pessoas e grupos inventem seus próprios fins no universo da cultura" (JEANSON ${ }^{11}$ apud TEIXEIRA COELHO, 1997, p.33).

[Lembramos que] ${ }^{12}$ a característica cultural do Movimento Hip-Hop é a sua face que mais se ressalta. Isto ocorre, pois, o Hip-Hop utiliza a cultura como a sua principal forma de se fazer notar, se fazer sentir no universo urbano das cidades. (...) Ao se fazer notar no universo urbano local, o Hip-Hop demonstra simbolicamente as "outras" partes que constituem a cidade, a existência e a importância destes jovens na vida urbana local. (RIBEIRO, 2006, pp. 16-17). 


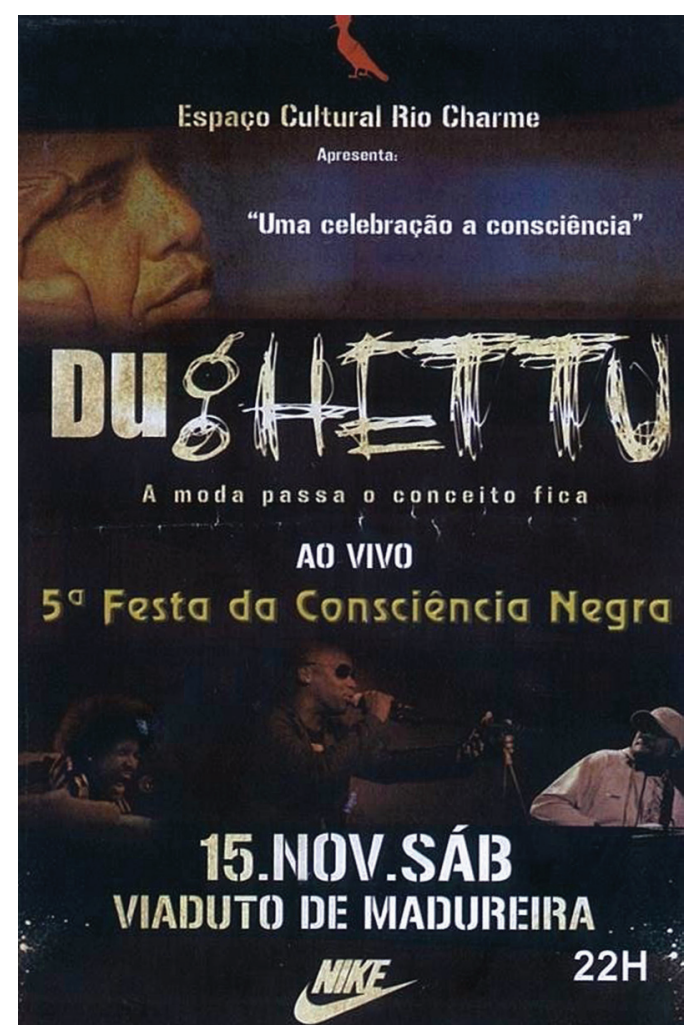

Figura 1: Flyer de divulgação da $5^{a}$ Festa da Consciência Negra realizada sob o Viaduto de Madureira em 2008 que confirma o caráter reivindica-tório e de afirmação da cultura negra do Movimento Hip-Hop, e que neste momento tomou como slogan a frase dita por Barack Obama "Sim nós podemos". Fonte: Arquivo particular dos autores outubro de 2008.
A ação cultural do Hip-Hop no Brasil se manifesta no espaço da cidade no sentido de aproximação com o outro através da diferença que se faz notar pelos simbolismos. É uma relação de alteridade em que o outro, ao interagir e retirar da sua cultura símbolos, re-interage na re-significação dos espaços urbanos vivenciados e resgatados como espaços de socialização da vida pública. Podemos dizer então que tal ação cultural se coloca como um dos elementos no processo que levam à urbanidade, elementos estes que se propõem "(...), a fazer a ponte entre as pessoas e a obra de cultura ou arte para que, dessa obra, possam (...) retirar aquilo que Ihes permitirá participar do universo cultural como um todo e aproximando-se uma das outras por meio da invenção de objetos comuns" (TEIXEIRA COELHO, 1997, p.33).

Teixeira Coelho coloca ainda, que nesse sentido a ação cultural, expressa nada mais que uma "ação sociocultural" que "tende a colocar uma pessoa,

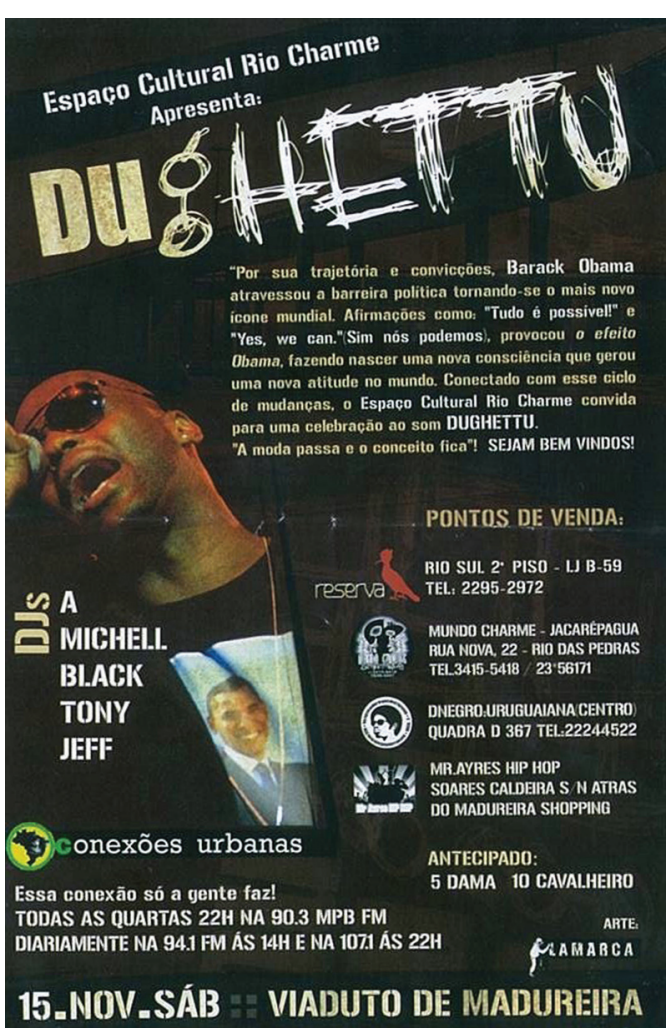

um grupo ou uma comunidade, em condições de exprimir-se em todos os aspectos da vida social (...). [As pessoas devem se expressar de forma autônoma em que daí flua] um benefício claramente caracterizado como social". (TEIXEIRA COELHO, 1997, p.34). A ação nasce no indivíduo ou grupo que se remete a sua localidade para então se tornar "globalizante".

Acreditamos então que o Hip-Hop como cultura detém o potencial de urbanidade, ela se hibridiza facilmente com qualquer cultura local, pois sua base é ideológica, fundada em objetivos comuns não somente às culturas negras, mas também as periféricas observadas em diversas localidades mundiais, pois, sabe que "é preciso reconhecer a pluralidade, a diversidade e as diferentes realidades que podem ser parecidas em alguns aspectos, porém não são iguais como um todo, tendo em vista que essa cultura é um reflexo da sociedade, tanto para o bem quanto para o mal" (DJ DEF YURI, 2005). Por isto acreditamos que a cultura do Hip-Hop, 
${ }^{13}$ Ramal de trem da Central do Brasil.

${ }^{14}$ Antigo ramal da Leopoldina, atualmente com partida da Central do Brasil.

Figura 2: Localização do Projeto Rio-Charme e da CUFA Madureir. Fonte: Imagem Google (acessada em Brasil: 19 nov 2008 15:28h). por sua vocação à exaltação ao modo de vida local, serve "para reestruturar o espaço público, para restaurar práticas de convivência, ou como caminho para a paz e a reconciliação" (OCHOA GAUTIER, 2003, p.62) no circuito de relações de urbanidade, entre troca de experiências como práticas sociais.

\section{A experiência da Ação Cultural Hip-Hop sob o Viaduto de Madureira}

Trabalhamos em nossa pesquisa o espaço público como espaço das relações sociais, aquela porção da cidade destinada ao encontro com o outro onde emergem as possibilidades de construção de urbanidade, por isto, um espaço conectado diretamente às culturas que o modela, um espaço em que se educa e é educado de volta. Contudo, observamos que nem sempre este espaço de encontro com o outro é idealizado, pensado simbolicamente para este fim, mas sim é fruto de um processo maior que abrange diversas escalas de organização urbana.

Nesse sentido, trazemos o foco para as ações culturais que se apropriam dos espaços públicos residuais da cidade e que acabam re-significando não-lugares em lugares. O não-lugar é um conceito proposto por Marc Augé e que se define por ser um espaço de passagem incapaz de produzir identidades, que não é relacional, nem histórico, e é ainda, um espaço que nunca se realiza totalmente, mas que é fruto da ação humana (AUGÉ, 2001, pp.73-74).

Importante ressaltar que o não-lugar se estrutura por pessoas em trânsito que não criam identidade com este, e é neste sentido que o Viaduto Negrão de Lima, mais conhecido como Viaduto de Madureira inaugurado na década de 1960, tem sua parte inferior entre as linhas de trem das estações de Madureira ${ }^{13}$ e Magno $^{14}$ (conhecida também como Estação Mercadão de Madureira), caracterizada como um simples espaço público de passagem espaço residual, e que encontra, em parte, re-significação através da atuação Movimento do Hip-Hop.

Historicamente o bairro de Madureira tem sua identidade cultural associada à presença do "Jongo da Serrinha" e mais tarde, pelas presenças das tradicionais escolas de samba Portela, Império Serrano e Tradição, o que revela a forte ligação local com a cultura negra.

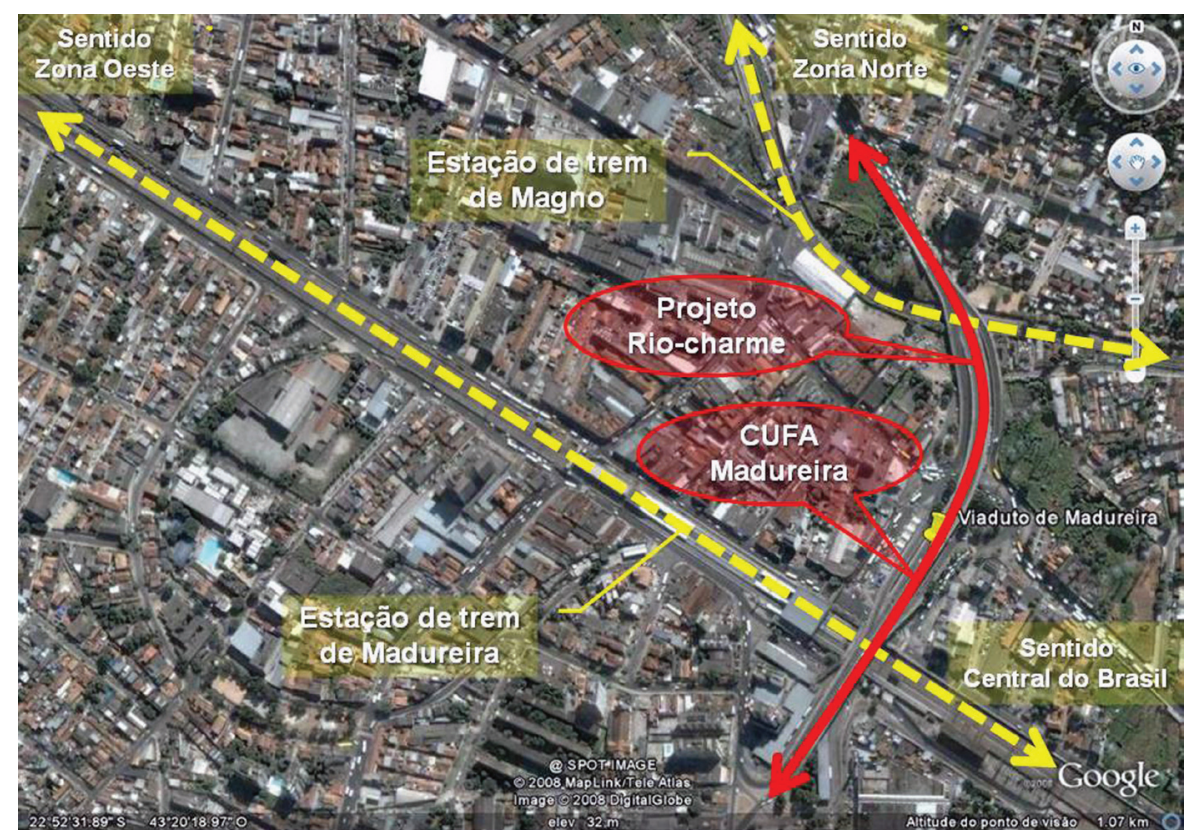



gov.br/bairroscariocas/index_bairro.htm.
${ }^{5}$ http://portalgeo.rio.rj

A ocupação territorial da região suburbana da cidade do Rio de Janeiro começou a se intensificar com a inauguração da Estrada de Ferro D. Pedro II, em 1858. Especificamente no bairro de Madureira isto ocorre em 1890 com a criação da estação da Estrada de Ferro que leva seu nome. Passa então a assumir características tipicamente urbanas com o estabelecimento de comércio varejista, e no final da década de 1930 indústrias, que continuaram crescendo nas décadas seguintes (ABREU, 1997). Hoje, Madureira é um bairro da Zona Norte da cidade, com ocupação industrial, residencial e comercial, caracterizando-se como um bairro de ocupação mista. Segundo dados de 2003 da Prefeitura do Rio de Janeiro ${ }^{15}$, Madureira ocupa uma área de 378,76 ha, com altíssima taxa de urbanização $(99,93 \%)$, e possui uma população de 49.546 habitantes, distribuídos em 15.400 domicílios (media de 3,21 habitantes por domicílio).

\section{Espaço Cultural Rio Hip-Hop Charme}

${ }^{16}$ À época, além de ser um dos fundadores do baile, dividia os toca-discos com os DJ's "Lopy, Michel, Cali e A". (E-BLACK, 2008)

${ }^{17}$ Conhecidos como "Leno, Pedro, Edinho e Xandoca". (E-BLACK, 2008)

${ }^{18}$ O Projeto de Lei $n^{\circ} 1910$ de 2000 torna oficial o "Espaço Cultural Rio-Charme", e o Projeto de Lei $n^{\circ} 1661$ de 2003 altera o nome deste para "Espaço Cultural Rio Hip-Hop Charme".
Segundo o DJ Marki New Charm ${ }^{16}$ (E-BLACK, 2008), no final de 1992, o grupo que organizou o bloco carnavalesco "Pagodão de Madureira" 17 em maio de 1990, é convidado por César Athaíde, para organizar um projeto que envolvesse toda a população do subúrbio denominado o "Projeto Charme na Rua". Então, o grupo propôs primeiramente como lugar a Praça Patriarca, depois a marquise da Loja Caricia. Mas foi somente a partir dos contatos políticos estabelecidos por Athaíde, que o grupo conseguiu autorização para usar sob o Viaduto de Madureira, na Praça das Mães. Já segundo MF Jones, uns dos atuais anfitriões do baile (E-BLACK, 2008),

[sic] (...) Tudo começou de uma brincadeira: nós éramos camelôs em Madureira e montamos Shopping Rua, ou seja, comprávamos os modelos das roupas dos playboys e dávamos nosso jeito vendendo as cópias do artigo original bem abaixo do preço pro povão que não tinha condições de se vestir bem. Com aquele lucro, tinha o nosso lazer que era no Vera Cruz (baile do DJ Corello no bairro de Abolição). Mas era a lei da selva: na nossa profissão, quem chega tarde perde o melhor ponto, e como nós chegávamos tarde do baile, a gente ficava prejudicado. Então, o César Negão (que Deus o tenha!) falou pra mim: "pô Jones, nós temos que fazer o nosso baile"! Mas fazer aonde? A Gente é camelô! "Que nada, vamos fazer debaixo do Viaduto porque ali ninguém vai reclamar nada"! Foi uma idéia meio maluca; na época eu tinha um trailer, que a minha ex-mulher administrava, e como lá era aberto, a gente resolveu cobrir os custos do baile com a cerveja que fosse vendida nele. E assim, eu, Cesar Negão, Mico e mais uma outra rapaziada fizemos o Chame na Rua, que hoje [é conhecido como], Rio Charme. (E-BLACK, 2008)

Com o falecimento de César Athaíde, seu irmão Celso Athaíde, num ato de preservação da construção da identidade da cultura black no bairro de Madureira e em memória ao seu irmão, decide manter o projeto vivo sob as estruturas do viaduto. Esta era a época de auge do movimento Hip-Hop carioca, e por este movimento não concordar com a violência crescente nos bailes funk na Cidade do Rio de Janeiro, aos poucos o Hip-Hop se fez cada vez mais presente no baile Charme na Rua, hibridizando-se com este e dando origem ao que Ribeiro convencionou chamar de New Charme (2006, p.67).

Nesse ponto, abrimos um parêntese para ressaltar a reação à violência, uma das ideologias do movimento Hip-Hop, ou seja, neste sentido a "cultura e as artes" que modelam a cultura Hip-Hop se colocam como uma "estratégia para transformar os hábitos do ódio e da vingança que se acumulam no ciclo de violências, [e ainda como] possibilidade de construção de espaços de participação onde só existe exclusão" (OCHOA GAUTIER, 2003, p.75).

O baile do Viaduto de Madureira passa então, a ser uns dos locais na Cidade do Rio de Janeiro de concentração popular de jovens vindos de todos os bairros da cidade, responsável pela difusão da cultura negra no Estado. No abarco deste processo, em 1995, o baile é reconhecido pelo Governo do Estado do Rio de Janeiro, como um instrumento essencial à cultura do bairro, tal como as escolas de samba e o jongo, ultrapassando as barreiras simbólicas do bairro e se enraizando como uma rotina cultural da cidade do Rio de Janeiro. Em julho de 2000 o "Projeto Charme na Rua" é então rebatizado de "Projeto Rio Charme", e em 2003 o nome é alterado novamente para "Espaço Cultural Rio Hip-Hop Charme" 18 .

Hoje, esse movimento black music presente sob o viaduto de Madureira, rompe suas fronteiras físicas, e se coloca na cidade através do simbolismo de 

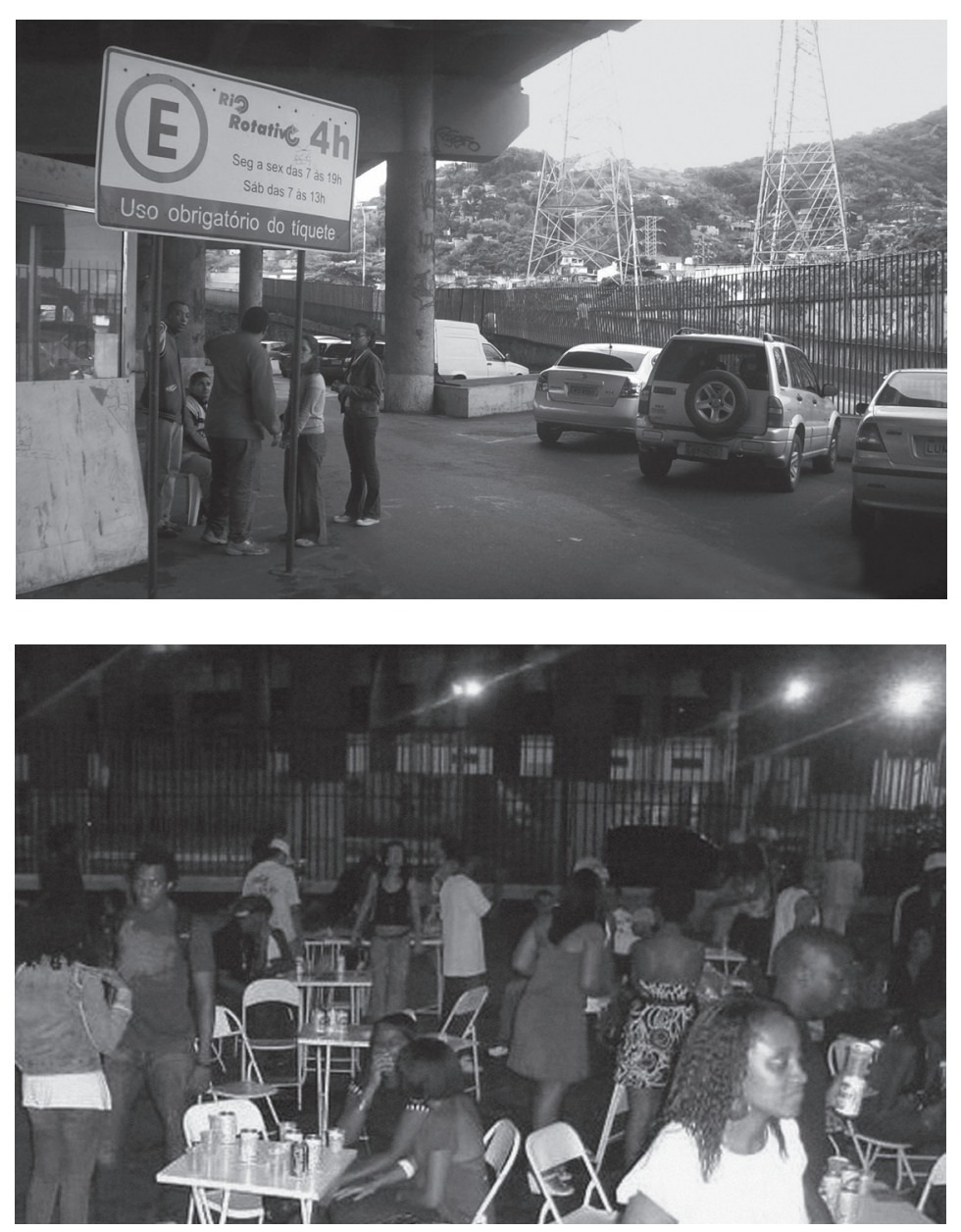

Figura 3: Área sob o Viaduto de Madureira onde ocorre o Projeto Rio-Charme nas noites de sexta e sábado. Durante o dia funciona como estacionamento. Fonte: Arquivo particular dos autores outubro de 2008.

Figura 4: Projeto Rio-Charme numa noite de sexta. Fonte: Arquivo particular dos autores outubro de 2008. resistência da cultura negra. Tanto é assim, que no aniversário de 15 anos do Rio Charme, o local escolhido, para realização da festa não foi o Viaduto de Madureira, mas sim o Circo Voador na Lapa. E, segundo Marcos Vinícius (E-BLACK, 2008) esta decisão se justifica na seguinte declaração:

Se você tivesse que fazer a festa de 15 anos da sua filha, você faria em casa? Primeiro, nós fomos convidados pelo Circo Voador. Isso pra nós soou como um prestígio! Nós impomos pra eles nossas regras quanto ao fazer este evento lá. Isto não quer dizer que nós não trabalhamos o nosso espaço e não fazemos os eventos devidos nele. Nosso baile é cotidiano a um evento que segue certa rotina todos os sábados. Se fossemos fazer uma festa pra homenagear nosso público, teríamos que presenteálos com uma festa atípica. Por isso o Circo Voador! (E-BLACK, 2008)
O Charme é uma construção feita a partir da música negra norte-americana. Sua origem, tem como ponto de partida o Rythm\&Blues, que se projetou mundialmente, incorporando a cultura de cada localidade (MARTINS, 2004, p.12). No Brasil e, mais especificamente, no do Rio de Janeiro, aproxima-se definitivamente da cultura Hip-Hop, e re-significa a cultura de rua carioca. Potencializado no Espaço Cultural Rio Hip-Hop Charme alcança visibilidade e converte-se, dentre as diversas formas de comunicação da juventude, em uma forma de reconstrução do sentido de lugar por meio da apropriação do espaço público residual. O baile Charme de Madureira "(...) é uma manifestação típica do Rio de Janeiro que se constitui, considerando, inclusive, a sua condição de ambiente de lazer e de entretenimento, em núcleo gerador de diversos espaços sociais" (RIBEIRO, apud MARTINS, 2004, p.31). 
19 Programa Nacional de Segurança Pública com Cidadania.
Figura 5: Área sob o Viaduto de Madureira onde se estabelece a CUFA. Fonte: Arquivo particular dos autores - outubro de 2008.

\section{Centro Cultural CUFA Madureira}

A Central Única das Favelas CUFA foi criada a partir da união entre jovens de várias favelas do Rio de Janeiro, majoritariamente de negros "que buscavam espaços para expressarem suas atitudes, questionamentos ou simplesmente sua vontade de viver" (CUFA, 2008). Constitui-se atualmente como uma organização não governamental, reconhecida por sua inserção política, social, esportiva e cultural. O Hip-Hop é sua principal forma de expressão, e também a sua ferramenta na integração e inclusão social das periferias urbanas.

Por ser um movimento que, há 20 anos, sobrevive se delineando nos guetos brasileiros mesmo sem o apoio da mídia, [que] cresce e se fortalece a cada dia, arrebatando admiradores de todas as camadas sócio-econômicas e deixando para trás o rótulo de "cultura do excluído". Ao longo de sua existência, o Hip-Hop vem criando um movimento forte, atraente, com grande potencial, e segue abrindo portas para novos nichos comerciais ainda não explorados. (CUFA, 2008).

A CUFA conta com o apoio e participação ativa do movimento Hip-Hop, através das atuações do Rapper MV Bill, e da Nega Gizza, que também é diretora do HUTÚZ, o maior festival de Rap da América Latina, produzido pela CUFA. O HUTÚZ é uma das ações culturais desenvolvidas pela CUFA, e se tornou uma marca para a cultura Hip-Hop. Outra forma de ação cultural da CUFA é a LIBBRA (Liga Brasileira de Basquete de Rua), que surgiu dentro do HUTÚZ em 2003, e que hoje "conta com o financiamento do Ministério da Justiça, por meio do PRONASCI19" (CUFA, 2008). Originariamente, o basquete de rua surge de uma brincadeira.

A quadra era o Armazém 5, do Cais do Porto do Rio de Janeiro. A cesta era uma lata de lixo. Os atletas eram jovens que naquele momento disputavam um improvisado "racha de basquete" com uma bola similar à bola laranja utilizada no basquete e, então, no Hutúz Rap Festival (uma tradicional manifestação de Hip-Hop) surgia no ano de 2001 o conceito do Basquete de Rua Nacional (uma variação que transita do basquete tradicional ao Streetball). (CUFA, 2008).

O primeiro Campeonato Nacional de Basquete de Rua foi organizado pela CUFA em 2002, "o Hutúz Basquete de Rua (HBR), que acontecia dentro do Hutúz Rap Festival". Hoje, apesar do HBR ainda existir, o evento cresceu, alcançando todo país, e é assim que a CUFA cria a LIBBRA que se tornou referência nacional. $O$ basquete de rua tem forte compromisso sócio cultural, capaz de aproximar jovens e transformar positivamente suas atitudes diante do outro. Também conhecido

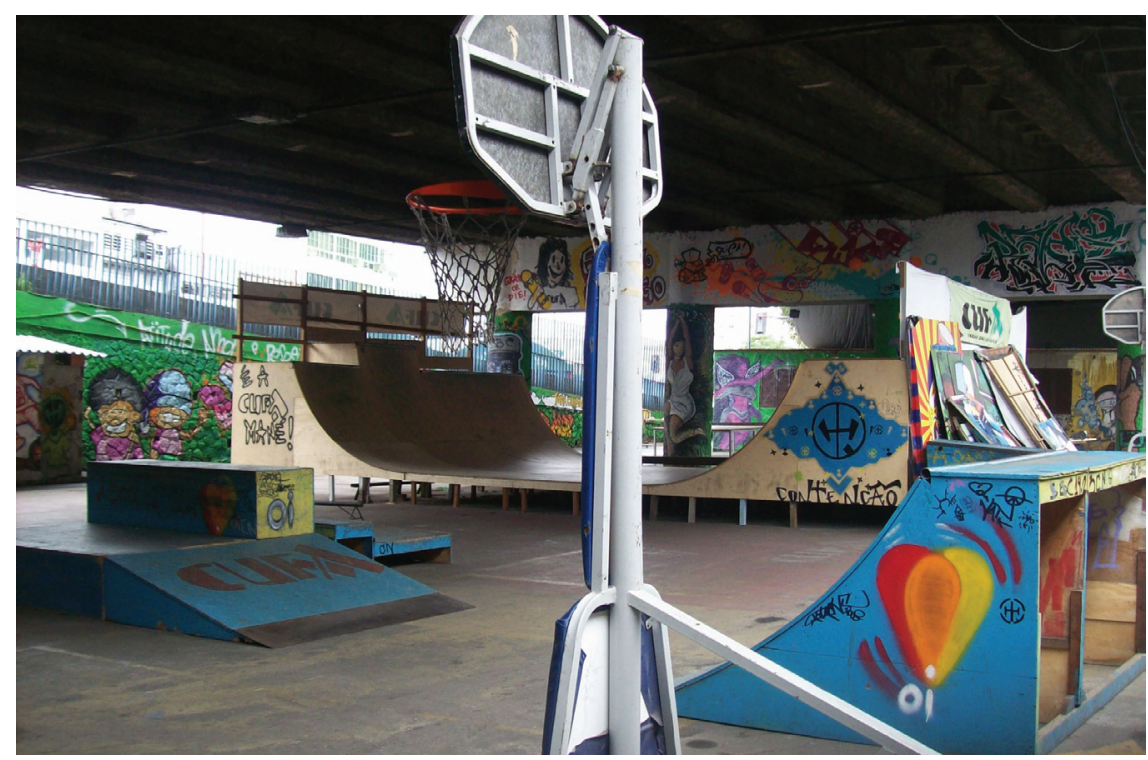


como "basquete-arte, (...) não se prende às regras convencionais, cria suas próprias" (CUFA, 2008).

A CUFA sempre atua com a perspectiva de ampliar suas formas e possibilidades de expressão e alcance sócio cultural, ao propiciar nas camadas menos privilegiadas da população a conscientização através da participação destas parcelas em oficinas de capacitação profissional, e entre outras atividades esportivas e culturais. O objetivo é elevar auto-estima do morador da periferia ao se defrontarem com um conhecimento que é capaz de oferecer novas perspectivas. A sua atuação está presente em 20 Estados Brasileiros, incluindo o Rio de Janeiro, que age como um "pólo de produção cultural desde 1999" (CUFA, 2008).

Dentre as atividades desenvolvidas pela CUFA, há cursos e oficinas de DJ; Break, Graffiti, Escolinha de Basquete de Rua, Skate, Gastronomia, Audiovisual e muitas outras. São diversas ações promovidas nos campos da educação, esporte, cultura e cidadania, com mão-de-obra própria (CUFA, 2008).

Atualmente, enquanto ação cultural, a CUFA, o HUTÚZ e a LIBBRA são identificadas no cenário urbano como marcas de "urbanidade", e atuam no Estado do Rio de Janeiro em cinco localidades; Acari, Complexo do Alemão (Pedra do Sapo), Cidade de Deus (CDD), Viaduto de Madureira, e mais recentemente, em Manguinhos. A base de Manguinhos foi inaugurada no "dia da favela20" em 04 de novembro de 2008.

Dentro da política de atuação da CUFA, os projetos sociais implantados nas suas sedes, se constituem como o fio que conduz a vitalidade diária de sua atuação. Especificamente no Viaduto de Madureira, até novembro de 2008, data que concluímos os levantamentos de campo, os projetos em desenvolvimento eram: Esporte, através da LIBBRA; Oficinas, de basquete e audiovisual com apoio do Ministério do Trabalho; Capacitação Profissional em gastronomia com apoio do Ministério do Turismo em parceria com o Ministério do Trabalho; além das capacitações em moda e skate.

\section{Considerações Finais}

Procuramos demonstrar como a ação cultural HipHop, presente nas ruas, pode recuperar o sentido de lugar, aquele vivenciado afetivamente, num sentido que aponta para a revitalização espontânea dos ambientes de que se apropriam e na resignificação cotidianamente dos espaços públicos residuais da cidade. O Movimento Hip-Hop tem fortes ligações com o movimento negro, e metodologicamente se insere no contexto de nossa pesquisa no bairro de Madureira, que já detém esta característica desde sua origem manifesta pelo Jongo e pelo Samba. Assim, identificamos que está na cultura do lugar acolher e reproduzir para as demais áreas da cidade formas de comunicação que refletem o pensamento das periferias urbanas. Neste aspecto lembramos que a cultura que se enraíza facilmente em Madureira "serve para reestruturar o espaço público, para restaurar práticas de convivência, ou como caminho para a paz e a reconciliação" (OCHOA GAUTIER, 2003, p.62).

Outra característica importante se relaciona a palavra "rua" presente em quase todas as ações sócio culturais do Hip-Hop. Nestas, a rua não representa o mero espaço de circulação, e sim, incorpora valores que a re-significam em lugar de permanência, onde se experimenta a vida pública cotidiana. Como observamos em nossa exposição, o termo Hip-Hop engloba todas as manifestações de rua (CARMO, 2003), e mesmo com origem nas ruas dos guetos norte-americanos, encontra nas ruas brasileiras o lócus ideal para sua hibridização e multiplicação, reafirmando-se como ação cultural, que como já citado por Gil é o "espaço privilegiado de realização da cidadania e inclusão social" (GIL, 2003, p.9).

A Cultura de Rua Hip-Hop revela-nos então seu potencial de urbanidade que encontra no Espaço Cultural Rio Hip-Hop Charme e na CUFA Madureira umas das formas de exercitar este potencial. Observamos que originariamente o Espaço Cultural Rio Hip-Hop Charme, chamava-se Charme na Rua, o que mais uma vez demarca a rua como lugar da vida pública. Lembramos neste aspecto, que o HipHop enquanto ação cultural reafirma a natureza "libertadora dos guetos", e pretende dar visibilidade, inicialmente pelo lazer, para aquele que vive nas periferias da cidade.

Já a CUFA atua através de várias frentes e no Viaduto de Madureira sua ação cultural se volta não só para as oficinas de capacitação profissional, ou para o lazer do skate e do esporte como um todo, mas esta também se coloca como forte 


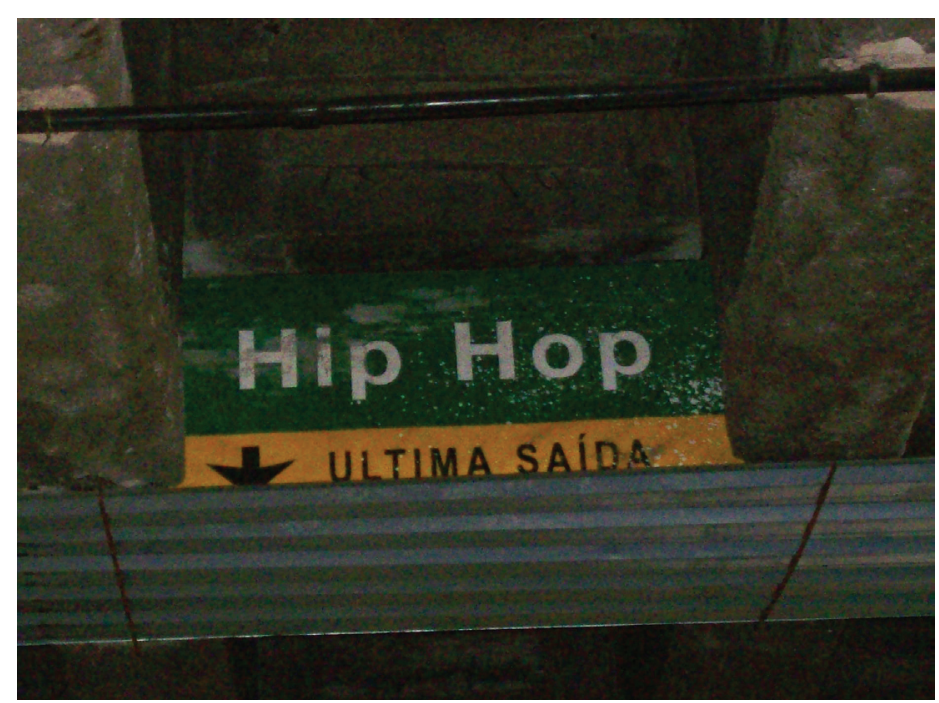

Figura 6: Área sob o Viaduto de Madureira onde se estabelece a CUFA. Detalhe da placa sobre a quadra de basquete que enuncia: "Hip Hop: ultima saída". Fonte: Arquivo particular dos autores outubro de 2008. interlocutora entre as juventudes de periferias que vêem a LIBBRA e o HUTÚZ, como um lugar de identificação que carrega o potencial de aumento da sua auto-estima.

De maneira conclusiva, afirmamos que a palavra rua nestas ações culturais transforma positivamente o sentido dos espaços públicos residuais, pois potencializa a resignificação que hibridiza culturas, e faz emergir ações culturais manifestas pelas comunidades locais. É a ação cultural local que transforma o mero espaço de circulação em lugar de encontro da vida pública, e recria diversos significados capazes de motivar a urbanidade. 0 Hip-Hop é uma forma de ação cultural que traz em sua filosofia esta potencialidade transformadora da urbanidade.

Os significados que esta ideologia é capaz de recriar são maiores do que a sua motivação inicial, pois esse é um movimento que tem vida própria e itinerante, pois não se restringe a um único lugar. Assim, o Hip-Hop pode ser considerado uma força que impulsiona e induz, é a própria cultura em ação que ultrapassa barreiras não só físicas, mas também socioculturais. Especificamente tomado como exemplo o caso do bairro de Madureira, o Hip-Hop extrapola seus limites físicos para encontrar em outras partes da cidade diferentes ambientes para a prática da inclusão social. Lembramos que para àqueles que são adeptos do seu sistema de idéias, este pode ser uma das "últimas saídas" encontradas como possibilidade multiplicadora da ideologia de paz, tolerância e manifestação do outro periférico como criador cultural.

\section{Referências Bibliográficas}

ABREU, Maurício de Almeida. Evolução urbana do Rio de Janeiro. Rio de Janeiro: IPLANRIO, 1997.

AUGÉ. Marc. O Sentido dos Outros: atualidade da antropologia. Tradução de Francisco Manuel da Rocha Filho. Petrópolis: Editora Vozes, 1999.

CANCLINI, Néstor Garcia. Culturas híbridas. São Paulo: EDUSP, 2000.

. Estratégias para entrar e sair da modernidade. São Paulo: EDUSP, 2006

CARMO, P. S. Culturas da rebeldia: a juventude em questão. São Paulo: Senac, 2003

CAUNE, Jean. Pratiques culturelles, médiation artistique et lien social. In: HERMĖS 20, 1996. http:// documents.irevues.inist.fr/bitstream/2042/14921/1/ HERMES_1996_20_169.pdf (acessado em Brasil: 09 nov 2008 14:00h).

CUFA. Central Única das Favelas. http://www.cufa.org.br. (acessado em Brasil: 27 out 2008 12:30h).

DJ DEF YURI. Hip-Hop - Hoje e Ontem. Viva Favela: Postado em 05 mai 2005. http://www.vivafavela.com.br/publique/cgi/public/cgilua.exe/web/templates/htm/princi$\mathrm{pal} / \mathrm{view}$ _rev_0016.htm?editionsectionid=16\&user= reader\&infoid=41609 (acessado em Brasil: 09 nov 2008 15:30h). 
E-BLACK. 15 anos de Rio Charme $\mathrm{O}$ bairro das escolas de samba tradicionais e do jongo comemora a debutância de sua filha mais nova: a black music. In: E-BLACK. http://www.pcg.com.br/eblack/36.htm (acessado em Brasil: 21 set 2008 18:00h).

FARIA, Hamilton. Políticas Públicas de Cultura e Desenvolvimento Humano nas Cidades. In: BRANT, Leonardo (org) Políticas Culturais Vol. 1. São Paulo: Manole, 2003, pp. 35-54.

GIL, Gilberto. Apresentação. In: UNESCO. Políticas culturais para o desenvolvimento: uma base de dados para a cultura. Brasília: UNESCO Brasil, 2003, pp.9-10. http://unesdoc.unesco.org/ images/0013/001318/131873por.pdf (acessado em Brasil: 21 set 2008 17:20h).

HUET, Bernard. Espaços públicos, espaços residuais. In: Os Centros das Metrópoles. (organização) Marco Antonio Ramos de Almeida. São Paulo: Editora Terceiro Nome. 2001, pp.147-151.

JACOBS, Jane. Morte e Vida de Grades Cidades. São Paulo: Editora Martins Fontes, 2000.

MARTINS, Carlos Henrique dos Santos. Os bailes de charme: espaços de elaboração de identidades juvenis. In: Ultima década, nº 22. Valparaíso: CIDPA, 2005, pp. 39-62.

O Charme: Território Urbano-Popular de Elaboração de Identidades Juvenis. Dissertação (Mestrado em Educação) Universidade Federal Fluminense - UFF/RJ, Niterói-RJ, 2004. http://www. uff.br/pos_educacao/joomla/images/stories/Teses/ carloshenrique.pdf (acessado em Brasil: 27 out 2008 13:50h)
OCHOA GAUTIER Ana María Indicadores culturais para tempos de desencanto. In: UNESCO. Políticas culturais para o desenvolvimento: uma base de dados para a cultura. Brasília: UNESCO Brasil, 2003, pp.61-81. http://unesdoc.unesco.org/ images/0013/001318/131873por.pdf (acessado em Brasil: 21 set 2008 17:20h)

RIBEIRO, Christian Carlos Rodrigues. O Movimento Hip-Hop como gerador de urbanidade: um estudo de caso sobre gestão urbana em Campinas. Dissertação (Mestrado em Urbanismo) Pontifícia Universidade Católica de Campinas, Campinas: Escola de Arquitetura e Urbanismo, 2006. http://www.bibliotecadigital.puc-campinas.edu. br/tde_busca/arquivo.php?codArquivo=106 (acessado em Brasil: 27 out 2008 12:40h).

SAFIRE, William. On Language: The rap on Hip-Hophop. The New York Times Magazine. In: http:// pt.wikipedia.org/wiki/Rap (acessado em Brasil: 17 out 2008 13:20h)

SENNETT, Richard. O Declínio do Homem Público: As Tiranias da Intimidade. São Paulo: Companhia das Letras, 1993.

TEIXEIRA COELHO. Usos da cultura: políticas de ação cultural. Rio de Janeiro: Paz e Terra, 1986.

Dicionário Crítico de Política Cultural. São Paulo: lluminuras, 1997.

WERTHEIN, Jorge. Introdução. In: UNESCO Políticas culturais para o desenvolvimento: uma base de dados para a cultura. Brasília: UNESCO Brasil, 2003, pp. 9 -20. http://unesdoc.unesco.org/ images/0013/001318/131873por.pdf (acessado em Brasil: 21 set 2008 17:20h) 


\title{
The experience of the Cultural Action of the Hip-Hop Movement under the viaduct of Madureira in Rio de Janeiro
}

Emika Takaki; Glauci Coelho

\begin{abstract}
We try to give visibility to the Hip-Hop Movement as cultural action capable of enhancing the revitalization of residual public spaces in contemporary cities. We brought the example of the space under the Viaduct of Madureira in Rio de Janeiro, which had not only its image of passage place transformed, as its significance to become a place of meeting of the public life through the performances of the "Cultural Space Rio Hip-Hop Charme" and "CUFA Madureira". Our theoretical construct was based on research and searching at official websites of CUFA Movement and the Hip-Hop and also on theoretical arguments of hybrid cultures, cultural action and public space by some authors.
\end{abstract}

Keywords: public space, place, cultural action.

\section{La experiencia de la Acción Cultural del Movimiento Hip-Hop bajo el viaducto Madureira de Río de Janeiro}

Emika Takaki; Glauci Coelho

\section{Resumen}

Buscamos dar visibilidad al movimiento "Hip-Hop" como acción cultural capaz de potencializar la revitalización de espacios públicos residuales en las ciudades contemporáneas. Trajimos el ejemplo del espacio generado bajo el viaducto de Madureira en Rio de Janeiro, que tuve su imagen de lugar de paso transformado, además su referente simbólico al convertirse en lugar de encuentro de la vida pública mediante las actuaciones del "Espacio Cultural Rio Hip-Hop Charme" y de la "CUFA - Madureira". Nuestra construcción teórica fué basada en investigación de campo e información proveniente de sitios Web oficiales de la CUFA y del movimiento Hip-Hop, además de las argumentaciones teóricas sobre culturas híbridas, acción cultural y espacio público interpuestos por varios autores.

Palabras clave: espacio público, lugar, acción cultural. 